\title{
Nanosale Patterning of Two Metals on Silicon Surfaces using an ABC Triblock Copolymer Template
}

Masato Aizawa and Jillian M. Buriak

National Institute for Nanotechnology, Edmonton, Alberta, and the Department of Chemistry, University Alberta, Edmonton, Alberta, Canada T6G $2 G 2$.

Contact information: E-mails: maizawa@ualberta.ca, and jburiak@ualberta.ca

Figure S1. AFM images of $0.1 \mathrm{mM} \mathrm{HAuCl}_{4} / 0.9 \% \mathrm{HF}$ (aq) deposition on silicon to provide height information of these nanostructures (in the z-direction). (a) $1 \mathrm{~min}$, (b) 5 $\min$.

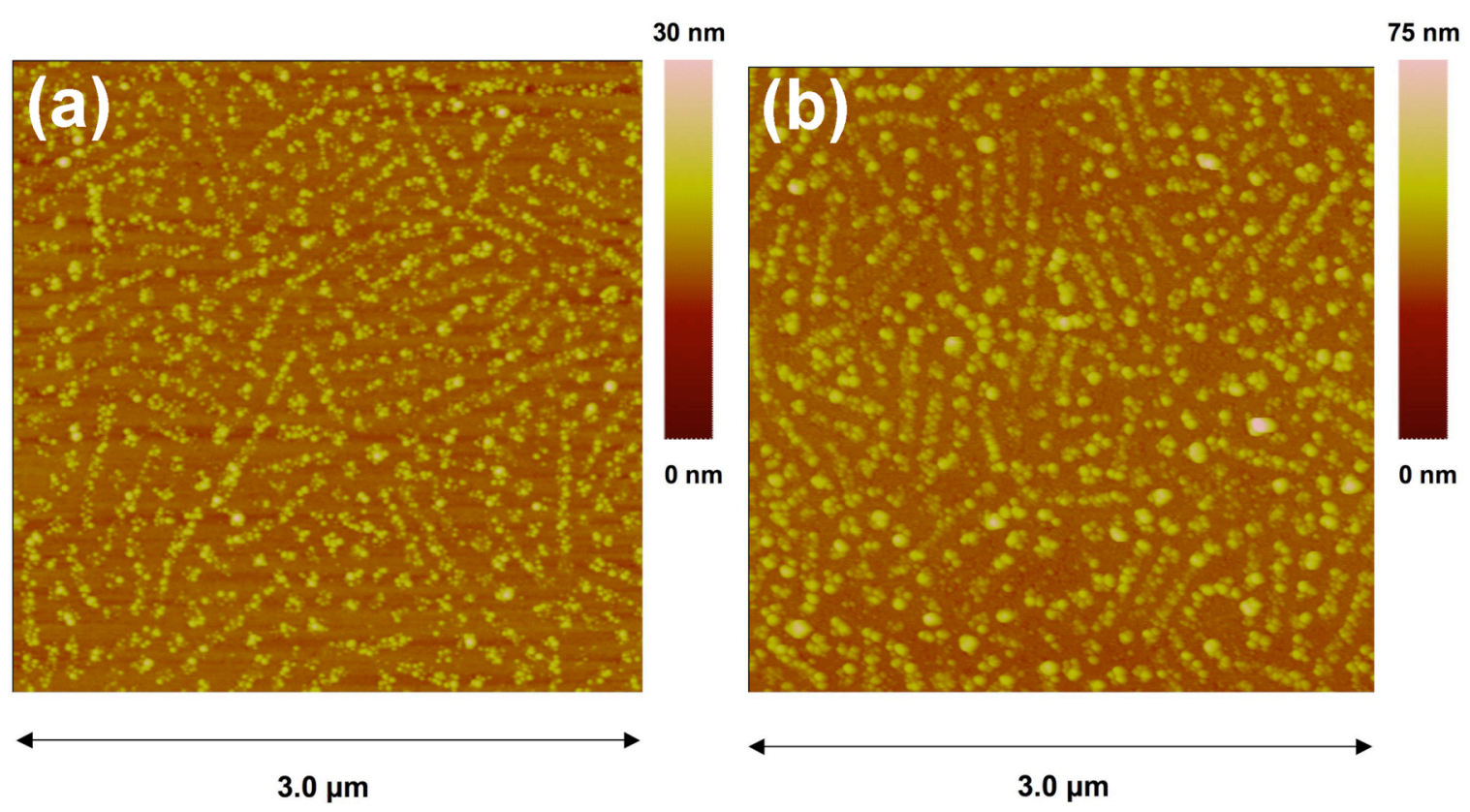

Figure S2. SEM images of $\mathrm{Ag}$ deposition on $\mathrm{SiO}_{\mathrm{x}}$-capped $\mathrm{Si}$ wafers using other silver salts: (a) $0.1 \mathrm{mM} \mathrm{AgClO} / 4.9 \% \mathrm{HF}$ (aq) for $5 \mathrm{~min}$, (b) $0.1 \mathrm{mM} \mathrm{AgCH} \mathrm{maO}_{3} \mathrm{CO} / 9 \% \mathrm{HF}$ (aq) for 5 min.
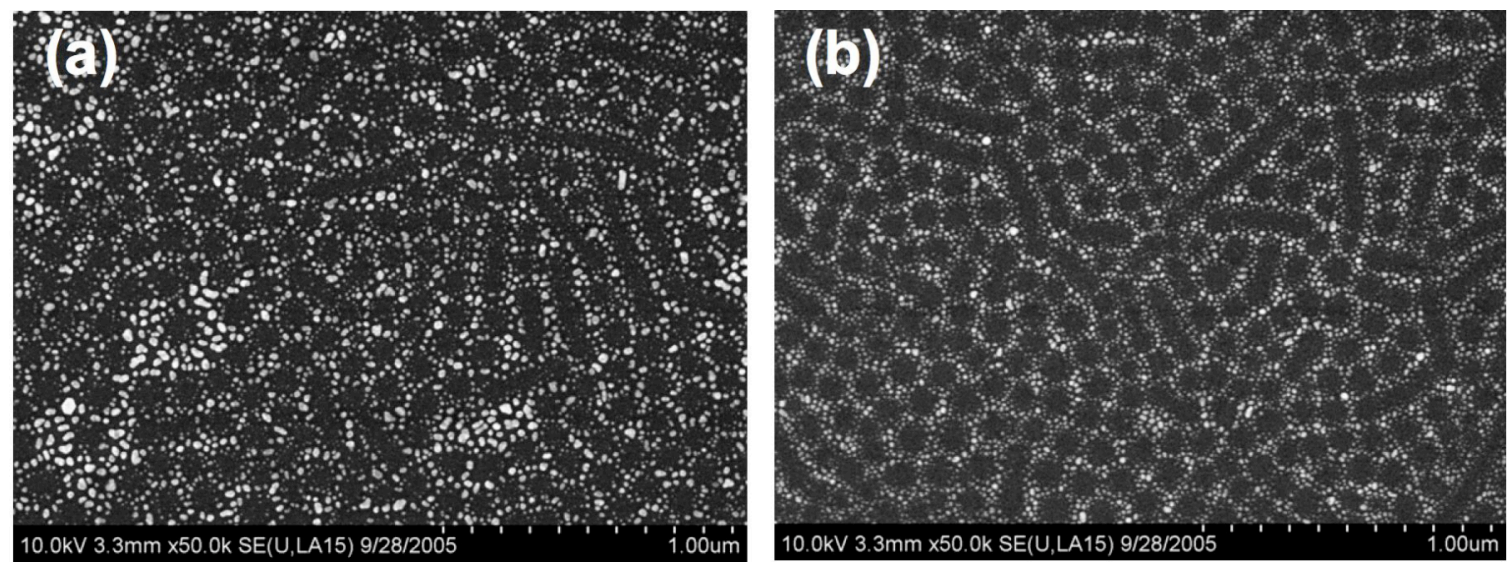
Figure S3. Higher resolution Scanning Auger Microscopy (SAM) of Au nanostructures on $\mathrm{SiO}_{x}$-capped Si chips: (a) SEM image, (b) Si KLL SAM, (c) Au MNN SAM, (d) fitting Au MNN (red) and Si KLL (green) signals over (a). The depositions were carried out from $0.1 \mathrm{mM} \mathrm{HAuCl} / 4 / 0.9 \% \mathrm{HF}$ (aq.) for $10 \mathrm{~min}$, followed by the polymer removal with toluene ultrasonication.

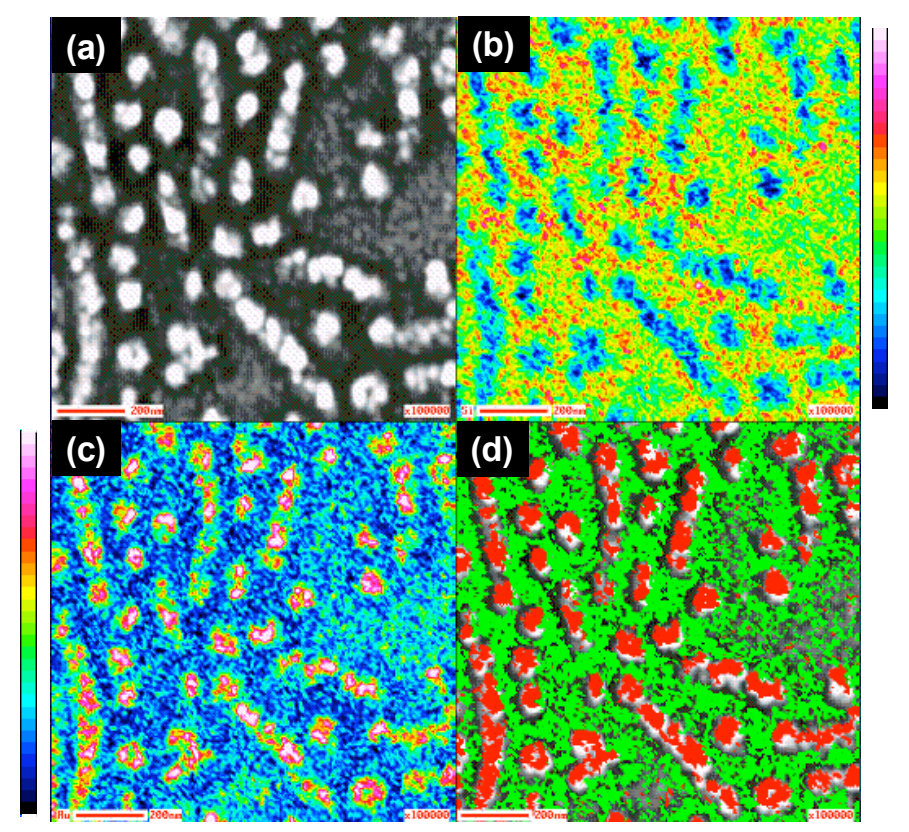

Figure S4. Higher resolution $\mathrm{SAM}$ of $\mathrm{Ag}$ nanostructures on $\mathrm{SiO}_{\mathrm{x}}$-capped $\mathrm{Si}$ chip: (a) SEM image, (b) Si KLL SAM, (c) Ag MNN SAM, (d) fitting Ag MNN (red) and Si KLL (green) signals over (a). The depositions were carried out from $0.1 \mathrm{mM} \mathrm{AgNO} / \mathrm{A} / 0.9 \%$ $\mathrm{HF}$ (aq.) for $10 \mathrm{~min}$, followed by polymer removal with toluene ultrasonication.

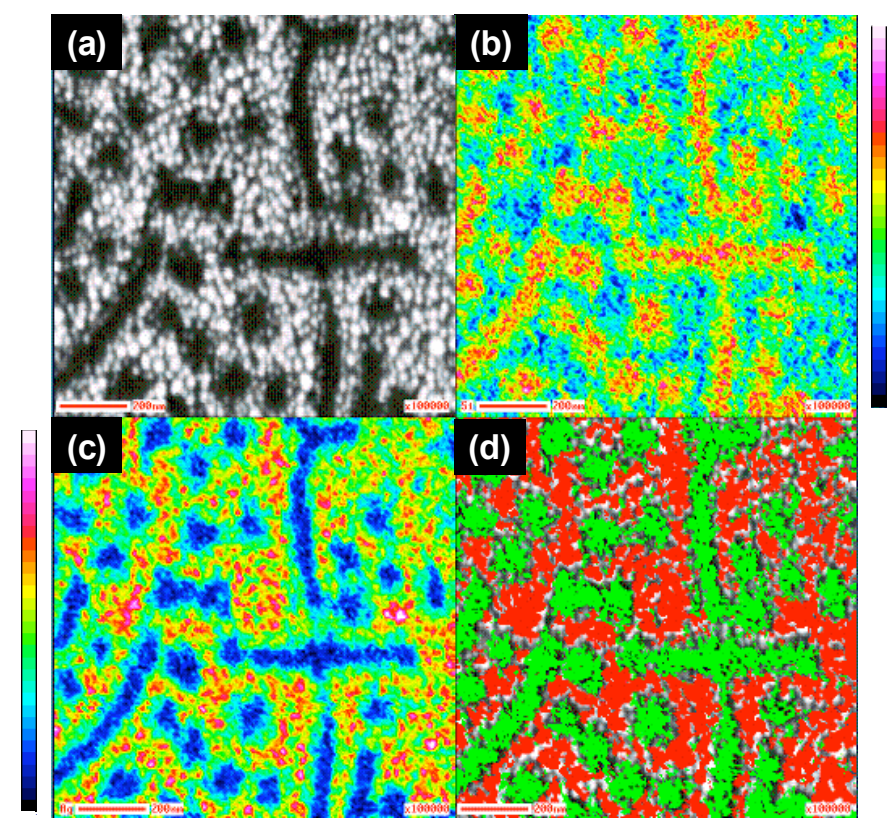


Figure S5. SEM images of Pt nanostructures on $\mathrm{SiO}_{\mathrm{x}}$-capped $\mathrm{Si}$ using PS- $b$-P2VP- $b$-PEO as a template. The Pt deposition was carried out from $0.1 \mathrm{mM} \mathrm{Na}_{2} \mathrm{PtCl}_{4} / 0.9 \% \mathrm{HF}$ (aq.) for $20 \mathrm{~min}$. The polymer was removed by $\mathrm{H}_{2} / \mathrm{Ar}$ plasma treatment for $20 \mathrm{~min}$.
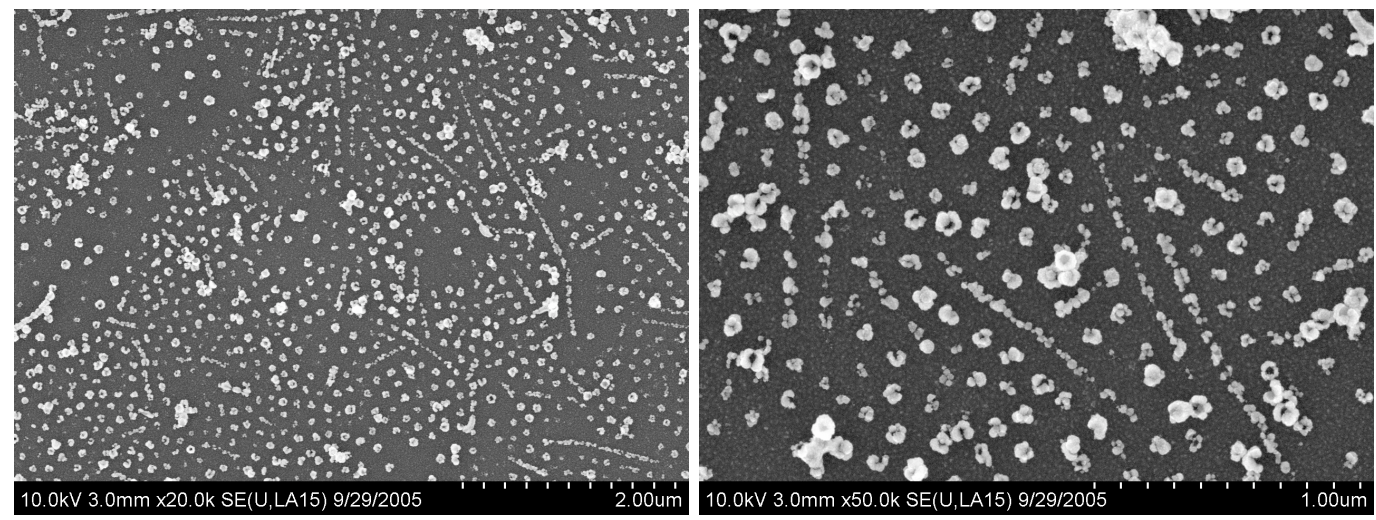

Figure S6. SEM images of Pd nanostructures on $\mathrm{SiO}_{\mathrm{x}}$-capped Si using PS- $b$-P2VP- $b$ $\mathrm{PEO}$ as a template. The Pd deposition was carried out from $0.1 \mathrm{mM} \mathrm{Na} 2 \mathrm{PdCl}_{4} / 0.9 \% \mathrm{HF}$ (aq.) for $20 \mathrm{~min}$. The polymer was removed by $\mathrm{H}_{2} / \mathrm{Ar}$ plasma treatment for $20 \mathrm{~min}$.
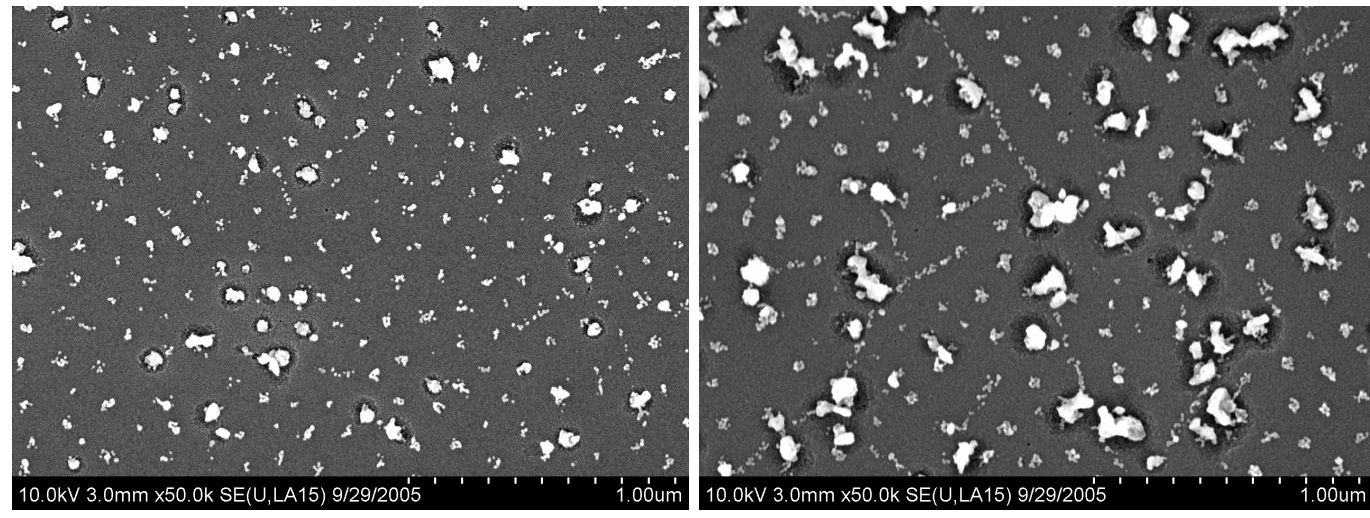

Figure S7. SEM images of $\mathrm{Cu}$ nanostructures on $\mathrm{SiO}_{\mathrm{x}}$-capped $\mathrm{Si}$ using PS- $b-\mathrm{P} 2 \mathrm{VP}-b$ $\mathrm{PEO}$ as a template. The $\mathrm{Cu}$ depositions were carried out from $0.1 \mathrm{mM} \mathrm{CuSO} / / 0.9 \% \mathrm{HF}$ (aq.) for $20 \mathrm{~min}$. The polymer was removed by $\mathrm{H}_{2} / \mathrm{Ar}$ plasma treatment for $20 \mathrm{~min}$.
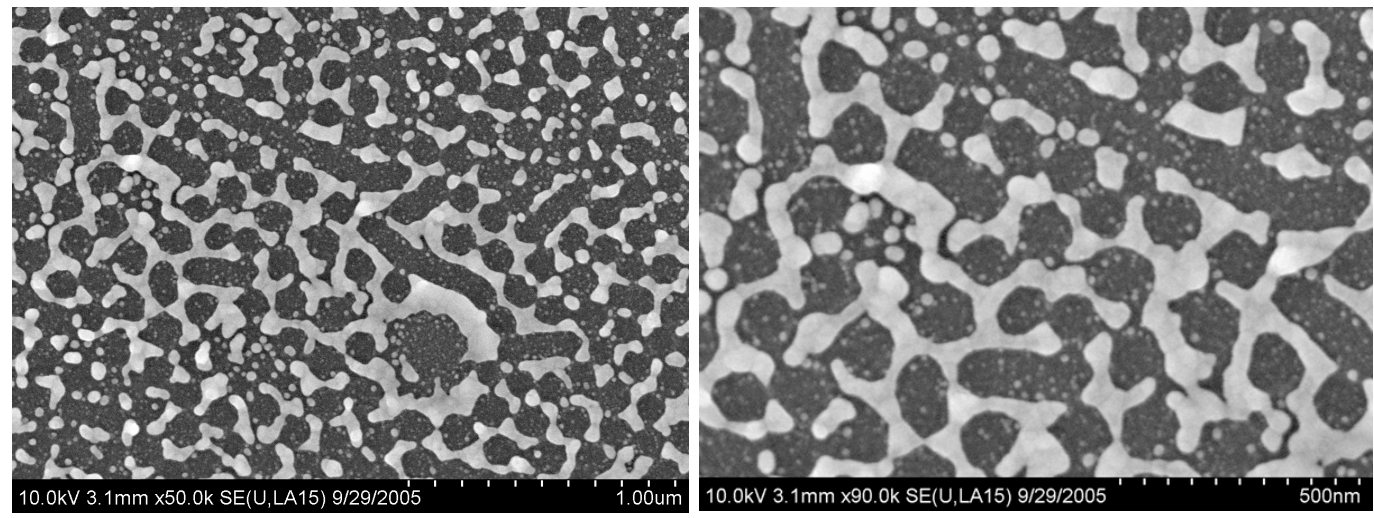
Figure S8. SAM of mixed $\mathrm{Au} / \mathrm{Ag}$ nanostructures on $\mathrm{SiO}_{\mathrm{x}}$-capped $\mathrm{Si}$ prepared by depositing Au, followed by Ag. (a) SEM image, (b) Ag MNN SAM, (c) Si KLL SAM, (d) Au MNN SAM. The deposition was carried out from $0.1 \mathrm{mM} \mathrm{HAuCl} / 4 / 0.9 \% \mathrm{HF}$ (aq.) for $5 \mathrm{~min}$ and $0.1 \mathrm{mM} \mathrm{AgNO} / 2.9 \% \mathrm{HF}$ (aq.) for $20 \mathrm{~min}$ in this order, followed by polymer removal with toluene ultrasonication.

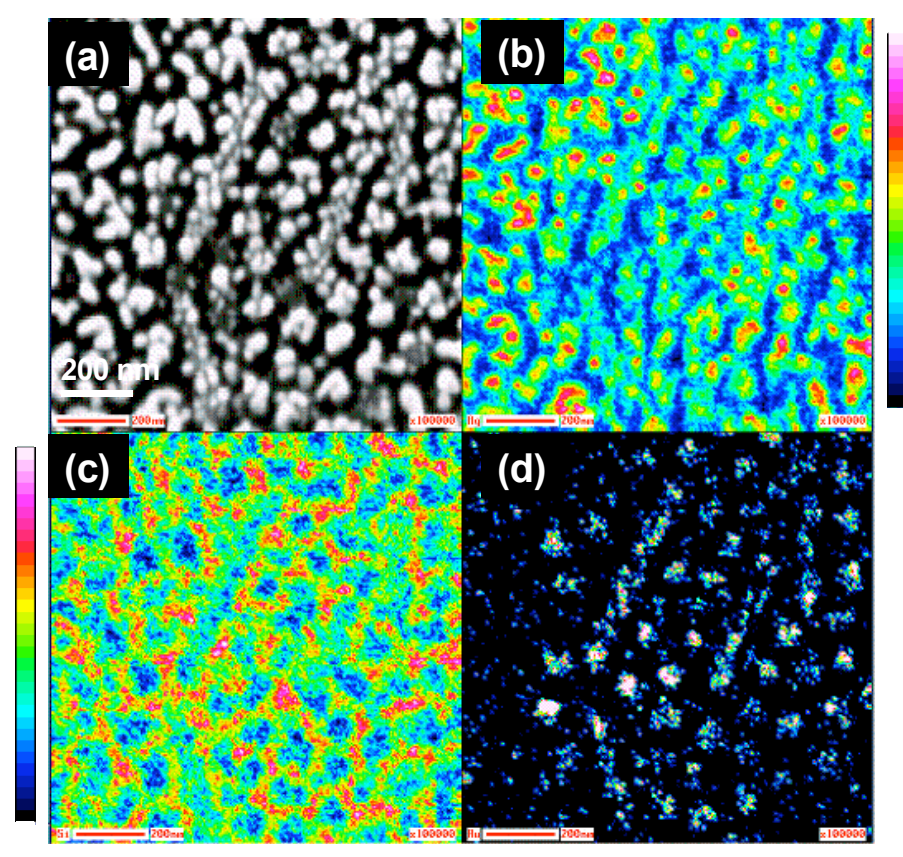

Figure S9. SAM of $\mathrm{AgAu}$ nanostructures on $\mathrm{SiO}_{\mathrm{x}}$ prepared by depositing $\mathrm{Ag}$, followed by $\mathrm{Au}$. (a) An SEM image. (b) Ag MNN. (c) Si KLL (d) Au MNN. The deposition was carried out from $0.1 \mathrm{mM} \mathrm{AgNO}_{3} / 0.9 \% \mathrm{HF}$ (aq.) for 5 min and $0.1 \mathrm{mM} \mathrm{HAuCl}_{4} / 0.9 \%$ HF (aq.) for $10 \mathrm{~min}$ in this order, followed by the polymer removal with toluene ultrasonication.

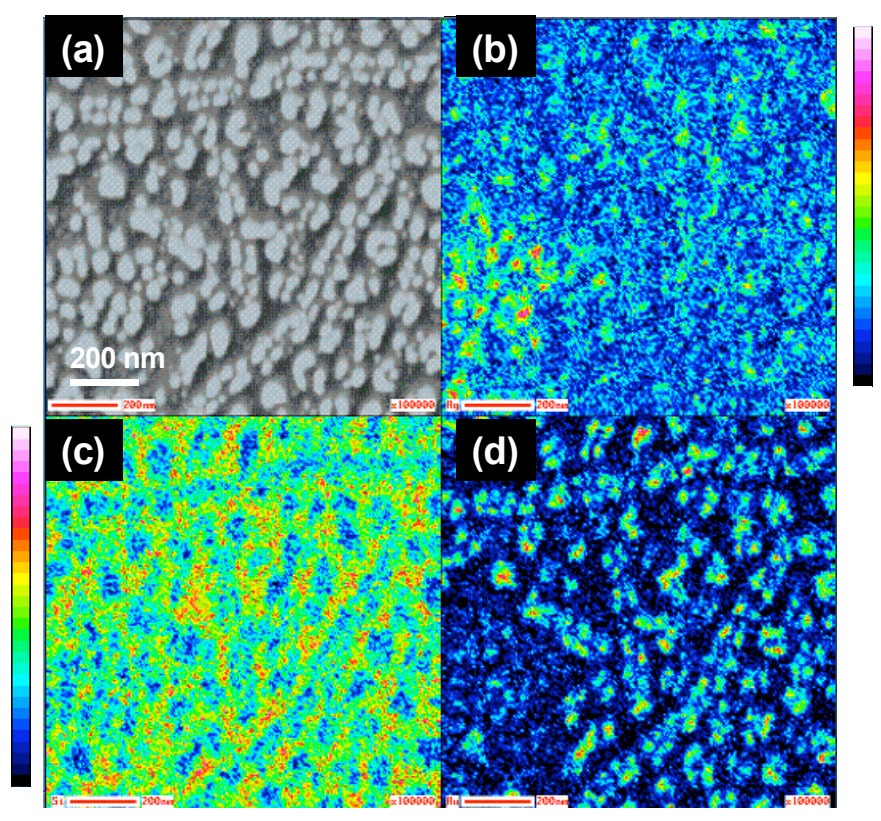


Figure S10. Au 4f (left) and $\mathrm{Ag} 3 \mathrm{~d}$ XPS (right) for $\mathrm{Au} / \mathrm{Ag}$ nanostructures on $\mathrm{SiO}_{\mathrm{x}}$. The deposition was carried out from $0.1 \mathrm{mM} \mathrm{HAuCl} / 0.9 \% \mathrm{HF}$ (aq.) and $0.1 \mathrm{mM}$ $\mathrm{AgNO}_{3} / 0.9 \% \mathrm{HF}$ (aq.) in this order, followed by polymer removal with toluene ultrasonication. The conditions of the spectra are as follows: (a) and (e) gold ion/HF solution 1 min only, (b) and (f) gold ion/HF solution for $1 \mathrm{~min}$, followed by silver ion/HF solution for $1 \mathrm{~min}$, (c) and (g) gold ion/HF solution for $1 \mathrm{~min}$, followed by silver ion/HF solution for $5 \mathrm{~min}$, (d) and (h) gold ion/HF solution for $1 \mathrm{~min}$, followed by silver ion/HF solution for $10 \mathrm{~min}$.
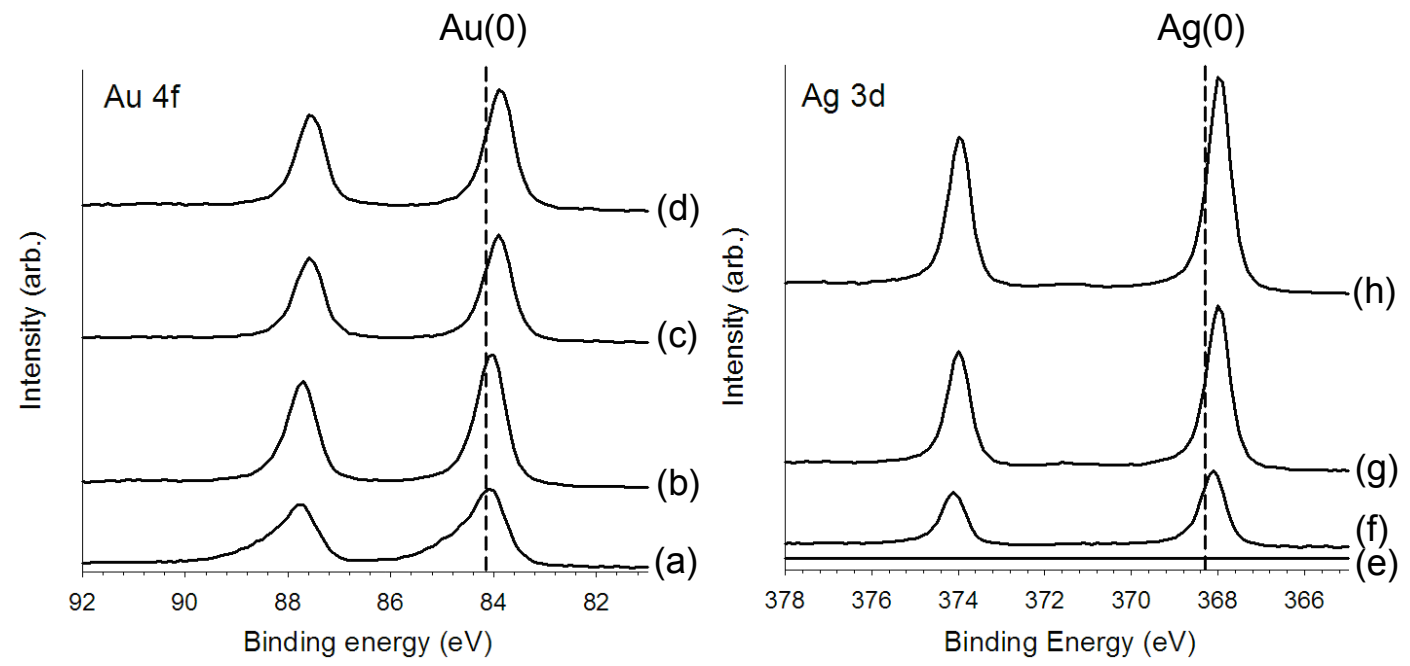

Figure S11. $\mathrm{Cu} 2 p$ XPS. (a) $\mathrm{CuSO}_{4}$ deposition on a polymer coated $\mathrm{SiO}_{x}$ in the presence of $0.9 \% \mathrm{HF}$ (aq.). Reduction of $\mathrm{Cu}^{2+}$ observed. The deposition was carried out from 0.1 $\mathrm{mM} \mathrm{CuSO}_{4} / 0.9 \% \mathrm{HF}$ (aq.). (b) Removal of the polymer with toluene ultrasonication has small effect on the $\mathrm{Cu}$ intensity since $\mathrm{Cu}$ nanoparticles are deposited in the thin PEO film.

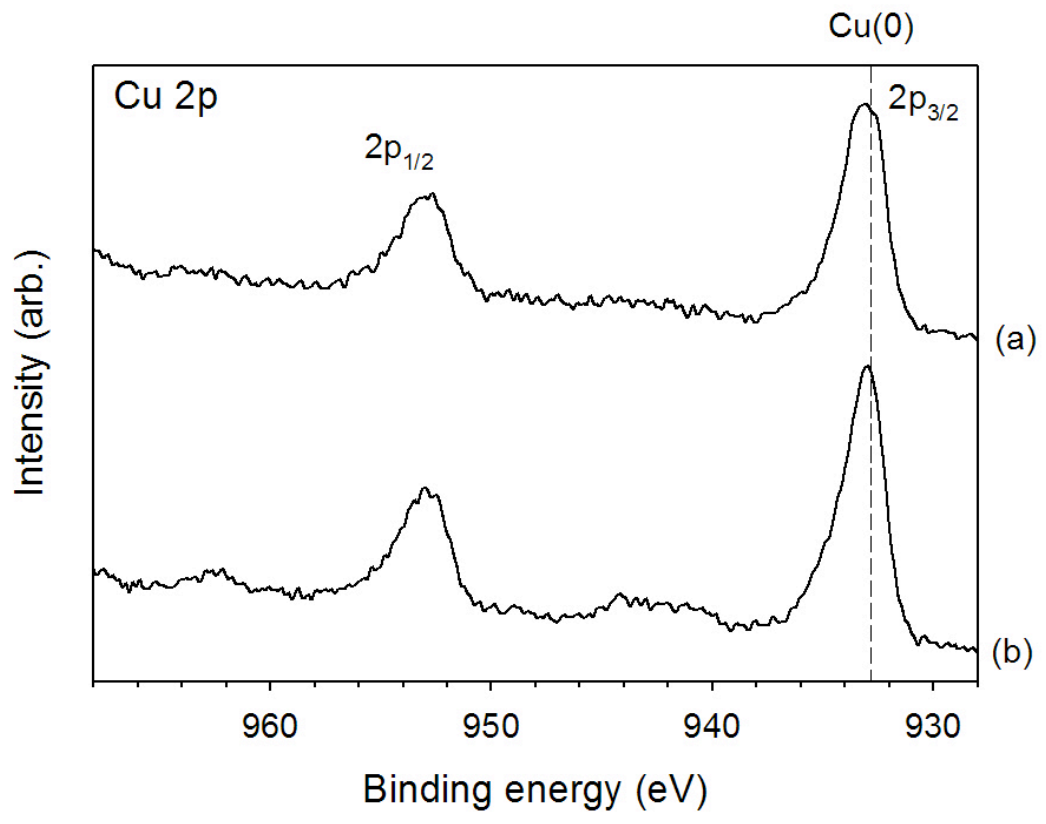

